\title{
the fairest of them all: 2000 - present
}

\author{
Joy Gregory
}

'The Fairest Of Them All' is a series of stills and quotations from a short film which discusses the desire to be blonde. This work uses the condition of 'Blonde' as a way of describing notions of shifting identities. This is a development of "The 'Blonde" website commissioned by inIVA 1998. This project was made in response to the growing presence of non-European 'blondes' on streets of the world's major cities. This work was first shown at Galeria Carmelo Gonzales, Havana as part of the 7 th Havana Biennale.
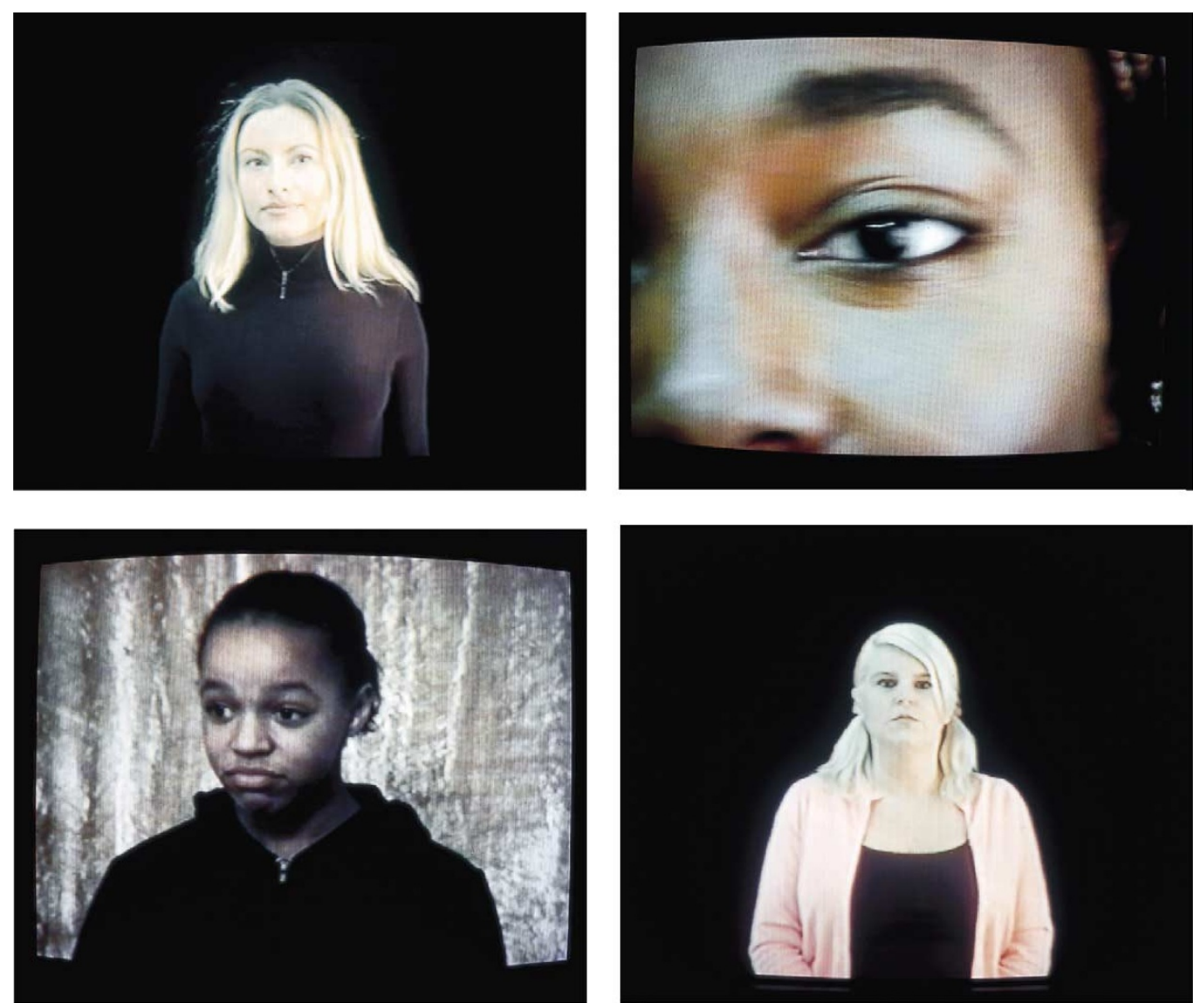

doi: $10.1057 /$ palgrave.fr. 9400040 